\title{
ÉTICA DEL CUIDADO EN ENTORNOS DE EDUCACIÓN SUPERIOR ANTE LA COVID-19
}

\author{
ETHICS OF CARE IN HIGHER EDUCATION \\ ENVIRONMENTS TO DEAL WITH COVID 19
}

\author{
Rosalba Contreras Ponce ${ }^{1}$ \\ María Isabel Loza Vaqueiro ${ }^{2}$
}

Recibido: 2021-10-05 / Revisado: 2021-11-18 / Aceptado: 2021-11-25 / Publicado: 2022-01-01

Forma sugerida de citar: Contreras-Ponce, R. y Lozada-Vaqueiro, M. I. (2022). Ética del cuidado en entornos de educación superior ante la COVID-19. Retos de la Ciencia. 6(12). 1-12. https://doi.org/10.53877/rc.6.12.20220101.01

\section{RESUMEN}

La pandemia por COVID-19 visibiliza la importancia del cuidado como una de las estrategias para detener los contagios, ante el paulatino regreso a clases para el ciclo escolar 2021-2022 en México, las instituciones educativas de todos los niveles enfrentan grandes retos. En el nivel superior, las medidas de seguridad tienen que responder a la oferta educativa, proyectos de investigación, trabajo de extensión universitaria, entre otros, lleva a plantear la pregunta: ¿qué están haciendo las universidades para evitar contagios y promover la corresponsabilidad del cuidado? En este sentido, el objetivo del artículo es compartir los aprendizajes y desafíos que ha significado la continuidad de un programa universitario de intervención comunitaria ante la pandemia y el retorno a actividades presenciales, con la finalidad de iniciar un diálogo sobre el cuidado entre las comunidades universitarias. Se plantea la ética de cuidado como punto de partida para visibilizar el trabajo de cuidado dentro de la vida pública y como estrategia para fortalecer los protocolos de bioseguridad. El artículo recupera la sistematización del programa, la discusión de grupos focales entre alumnos y egresados, así los protocolos de bioseguridad ante el regreso a actividades presenciales.

Palabras claves: ética de cuidado, educación superior, intervención comunitaria, protocolos de bioseguridad, Covid-19.

\footnotetext{
1 Estudiante del Doctorado Interinstitucional en Economía Social Solidaria, Universidad Autónoma Chapingo. México. E-mail: rcontreras4@hotmail.com / https://orcid.org/0000-0001-7397-6563

2 Profesora de asignatura ENES, Unidad León de la Universidad Nacional Autónoma de México. México. mlozav@enes.unam.mx / https://orcid.org/0000-0003-2003-5334
} 


\section{ABSTRACT}

The COVID-19 pandemic had made visible the importance of care as one of the strategies to stop contagions, given the gradual return to classes for the 2021-2022 school year in Mexico, educational institutions of all levels face great challenges. At the higher level, security measures have to respond to the educational offer, research projects, university extension work, among others, it leads to the question: what are universities doing to avoid contagion and promote shared responsibility of care? In this way, the objective of the article is to share the learnings and challenges that the continuity of a university program of community intervention in the face of the pandemic and the return to face-to-face activities has meant, in order to initiate a dialogue on care among university communities. The ethics of care is proposed as a starting point to make care work visible in public life and as a strategy to strengthen biosafety protocols. The article recovers the systematization of the program, the discussion of focus groups between students and graduates, as well as the biosafety protocols before returning to face-to-face activities.

Key Words: ethics of care, higher education, community intervention, biosafety protocols, covid-19.

\section{INTRODUCCIÓN}

A finales de 2019, se hizo público en la esfera internacional la aparición del coronavirus SARS-Cov-2 en China, nadie se imaginó la magnitud de la pandemia. El 11 de marzo de 2020 la Organización Mundial de la Salud (OMS), declaró que la COVID-19 pasaba de ser una epidemia a una pandemia, bajo este contexto, en México, el 16 de marzo de 2020 se publicó en el Diario Oficial de la Federación el acuerdo número 02/03/20 con la suspensión de clases "en las escuelas de educación preescolar, primaria, secundaria, normal y demás para la formación de maestros de educación básica del sistema educativo nacional, así como aquellas de los tipos medio superior y superior dependientes de la Secretaría de Educación Pública" (DOF, 16 de marzo 2020). El periodo de suspensión de clases comprendía del 23 de marzo al 17 de abril de 2020, sin embargo, se extendió por 17 meses.

En julio de 2021 el presidente de México señaló el regreso a clases para el ciclo escolar 2021-2022 a nivel básico, lo que generó posturas a favor y en contra, a pesar de que la primera fase de vacunación inició el 24 de diciembre de 2020, se acordó fuera de manera voluntaria y con respectivos protocolos de seguridad en cada nivel. A nivel superior, cada institución ha tomado las medidas pertinentes ante la pandemia, algunas no han regresado a clases, por tal razón, el 29 de septiembre el presidente hizo un llamado a las universidades para retomar hacerlo (Carrillo, 2021). El reto es mayor dentro de las universidades, los protocolos de seguridad deben responder a la diversidad de tareas que realizan, no sólo debe responder al regreso a aulas, sino también a aquellas de vinculación con otras instituciones $u$ organizaciones de la sociedad para cumplir con los objetivos establecidos dentro de los programas de licenciatura o posgrado, los proyectos de investigación, de extensión universitaria, de difusión de la cultura, entre otros.

La elaboración de protocolos de seguridad conlleva una discusión, análisis y propuestas sobre las medidas que deben tomarse para evitar o reducir el número de contagios. Desde la Universidad Nacional Autónoma de México se ha establecido protocolos de bioseguridad, además se generó la aplicación UNAM Salud COVID-19, que permite identificar los riesgos que enfrenta la comunidad universitaria de enfermar 
por SARS-CoV-2, es una herramienta digital que busca promover la colaboración, responsabilidad y el mayor cuidado entre quienes integran la población universitaria para ayudar a disminuir y evitar, en lo posible, las cadenas de contagio (GacetaUNAM, 2021).

En la Escuela Nacional de Estudios Superiores, Unidad León, UNAM (ENES León) el regreso paulatino de actividades semi-presenciales, se inicia en el primer semestre del calendario escolar 2022 que comprende de agosto a diciembre de 2021 (El financiero, 2021), con una serie de protocolos de bioseguridad que se deben seguir y están compilados en el Manual de Procedimiento de Bioseguridad para la ENES León \& San Miguel de Allende. En este contexto, se presenta el proceso de continuidad del Programa de Intervención Comunitaria (PIC) de la licenciatura en Desarrollo y Gestión Interculturales (DGI) durante la pandemia, el objetivo es compartir los aprendizajes y desafíos que ha presentado, con la finalidad de generar un diálogo para construir colectivamente alternativas y propuestas que respondan a los retos que implica el retorno paulatino de las actividades presenciales en diferentes espacios.

EI PIC retoma la ética de cuidado como punto de partida para visibilizar el trabajo de cuidado dentro de la vida pública y como estrategia para fortalecer los protocolos de bioseguridad. Como señala Boaventura de Sousa (2020) en La cruel pedagogía del virus, la COVID-19 está dejando aprendizajes y abre paso a reflexionar la forma en que se vive, desde este programa la pandemia abre la pauta para promover una ética de cuidado entre la comunidad universitaria y al mismo tiempo visibiliza el cuidado como un tema de la agenda pública, porque todo ser vivo requiere de él y es necesario para la reproducción de la vida. Durante la pandemia el programa llevó a la reflexión de la importancia del cuidado entre el alumnado, profesores, administrativos y la comunidad en general, vislumbrando la ética de cuidado como una de las estrategias para fortalecer los protocolos de bioseguridad. En este sentido, se comparte la experiencia del programa con un antes y un durante la pandemia, así como los aprendizajes y retos que implica el regreso a actividades presenciales.

\section{DESARROLLO}

La vida universitaria está marcada por un antes, durante y actual retorno a actividades presenciales por COVID-19, el Programa de Intervención Comunitaria de la licenciatura en Desarrollo y Gestión Interculturales no es la excepción. En este sentido, se contextualiza el programa, sus objetivos, etapas y la comunidad de intervención, se continúa con su implementación antes de la pandemia; después la forma en que se llevó a cabo durante el periodo de aislamiento y, por último, la ética de cuidado ante el retorno a actividades presenciales como una apuesta para fortalecer los protocolos de bioseguridad.

\section{Programa de Intervención Comunitaria}

El Programa de Intervención Comunitaria (PIC) inició en 2018 para fortalecer la formación de sus alumnos con el objetivo de generar un entorno significativo en el proceso de enseñanza-aprendizaje mediante su intervención en escenarios sociales concretos para la aplicación de los conocimientos y competencias adquiridos en clases, así como evaluar su futuro quehacer profesional y reflexionar sobre su pertinencia social (Programa de Intervención Comunitaria, 2018). El programa se lleva a cabo a través del taller de intervención comunitaria, en principio fue una asignatura complementaria sin créditos, en la actualidad es una asignatura optativa con créditos. 
La propuesta de Barbero y Cortés (2005) sobre trabajo comunitario fue uno de los referentes para delimitar el proceso de intervención del programa; si bien hay diversas perspectivas sobre en qué consiste y cómo se debe realizar el trabajo en comunidades la mayoría coinciden en que este no es asistencial, sino que busca el empoderamiento de las comunidades con las que se trabaja, estos autores señalan:

"[...] entendemos por trabajo comunitario un tipo de actividad que pretende la organización de poblaciones. Se trataría de una práctica organizativa que realizan los profesionales de la intervención social y en torno a ciertos objetivos colectivos. Lo que el trabajo comunitario pretende es abordar la transformación de situaciones colectivas mediante la organización y la acción asociativa. Se trata de una tarea que se encara con el reto de constituir y sostener un grupo (o varios) en torno a la elaboración y a la aplicación de proyectos de desarrollo social" (Barbero y Cortès, 2005, p. 18).

El escenario social concreto del PIC es la comunidad de San Juan de Abajo (SJA) en León, Guanajuato que se ubica al sur de la ciudad de León, es parte de los ocho polígonos de pobreza del municipio (IMPLAN, 2014), en el diagnóstico municipal (IMPLAN, 2019) se indica que más del $70 \%$ de la población presenta pobreza extrema. Cabe señalar que en los últimos 20 años la población de San Juan de Abajo se ha incrementado, la causa principal es el proceso de migración derivado de la venta de terrenos por parte de los ejidatarios, sin embargo, el proceso de urbanización es irregular dado que no se cumplen con los criterios establecidos para uso de suelo habitacional, además de la falta de cohesión social entre los nuevos habitantes por no compartir los mismos códigos culturales, al provenir de diferentes localidades del municipio o del estado, incluso de otros lugares del país.

De acuerdo al Censo de Población y Vivienda 2020 en los principales resultados por localidad (INEGI, 2021) en SJA habitan 7,559 personas, 3,728 son mujeres y 3,831 hombres; el promedio de hijos es de 2.45; el grado promedio de escolaridad es de 6.51 años, por debajo de la media nacional que es de 9.7; la población económicamente activa asciende a 3,263 ; el $31.7 \%$ de la población no tiene a afiliación a los servicios de salud, el $36.3 \%$ está afiliada a servicios de salud en el Instituto de Salud para el Bienestar, lo que indica que el $68 \%$ no cuenta con seguridad social por un empleo formal; existen 1,830 viviendas en la comunidad, de la cuales 1,639 son viviendas particulares habitadas, de éstas sólo disponen de agua entubada 315 , es decir, aproximadamente el $80 \%$ de la viviendas no cuenta con agua en su interior, el acceso a este vital líquido es un problema para la mayoría de su población; en cuanto al drenaje el $85.6 \%$ cuenta con este servicio; en los servicios de conectividad sólo el $2 \%$ de la viviendas cuenta con servicio fijo de teléfono, el $81.3 \%$ cuenta con teléfono celular y sólo 10\% disponen de Internet (Secretaría de Desarrollo Social, s/f). Los datos muestran la vulnerabilidad de las personas que habitan en SJA, situación que se complejiza con la pandemia.

La selección de la comunidad se dio a partir de la vinculación con el Centro de Desarrollo Comunitario en San Juan de Abajo de la Fundación León A.C. Se acordó que el programa fuera un espacio de encuentro e intercambio de experiencias entre la Universidad, la Fundación, la comunidad y de aquellos actores sociales que apostaran a mejorar las condiciones de vida de las personas, cada uno con sus propias acciones, pero de manera coordinada. En este contexto, se plantea el programa a tres años, con las siguientes apuestas: Fortalecer el proceso de enseñanza-aprendizaje de los alumnos de DGl; Contar con continuidad y presencia en la comunidad más allá de un periodo escolar; y la articulación con diversos actores sociales. El programa se planteó en 6 etapas, cada una vinculada con la duración de 
un semestre escolar: 1) Acercarse a la comunidad, 2) Establecer líneas de acción, 3) Intervención comunitaria, 4) Gestión social y autogestión, 5) Evaluación del proceso y 6) Experiencia referencial.

\section{Antes de la pandemia}

Las tres primeras etapas se realizaron sin presencia de la pandemia, es decir, el segundo semestre de 2018 y 2019. La primera etapa consistió en conocer tres de los ochos sectores de San Juan de Abajo, se hizo un diagnóstico general a través de recorridos por la comunidad, guías de observación, elaboración de mapas, entrevistas a representantes o líderes comunitarios, participaron alumnos de primer y tercer año. En la siguiente etapa, la del semestre enero-junio 2019, se retomaron los resultados de la primera etapa, con algunas modificaciones para continuar con la segunda etapa. De los tres sectores abordados en la primera etapa se optó por dar seguimiento a San Joaquín y Poniente Sur, se dejó el sector San Juan Bautista por el trabajo cercano que realiza Fundación León y los recursos limitados del programa. En esta etapa se elaboraron los diagnósticos participativos en los sectores San Joaquín y Poniente, se identificó la cohesión social como el eje central de intervención social con sus líneas de acción: Mejora del entorno, Espacios de convivencia, Organización vecinal y Sensibilización de problemáticas, participaron alumnos de primer, segundo y tercer año (García, Autora 1 y Autora 2, 2019).

La tercera etapa del semestre agosto-diciembre 2019 se comenzó con las actividades de intervención comunitaria, orientadas a fortalecer el tejido social de la comunidad de San Juan de Abajo, particularmente en los sectores San Joaquín y Poniente Sur. Se realizaron clases de zumba, juegos de mesa entre vecinos, actividades manuales, etc. Sobresale la creación de "Bertha la huácala viajera", es una caja con libros, juegos de mesa y un diario que recorrió los hogares de los sectores para fomentar la interacción entre los integrantes de la familia, la gente estableció las reglas y escribía en el diario su experiencia, la creación de Bertha implico la organización de una campaña dentro de la ENES, Unidad León para solicitar donaciones de juegos de mesa y libros, la respuesta de la comunidad universitaria fue generosa. (Autora 2 y Autora 1, 2019). En esta etapa, se inició un proceso análisis y reflexión sobre los límites y posibilidades del programa, considerando los recursos humanos como equipo y la falta de recursos económicos para la llevar a cabo otras actividades establecidas en las líneas de acción, tales como la creación de huertos comunitarios, la separación de basura para hacer composta, etc., por consiguiente, se planteó gestionar proyectos para fortalecer el proceso y los alumnos de segundo año formaron el Colectivo Estudiantil de Intervención Social (CEIS). Sin embargo, nadie se esperaba una pandemia a nivel mundial que modificaría la forma de interacción de las familias, la comunidad, el trabajo, la escuela, los amigos, etc., cambiando las prioridades y tratando de buscar respuestas a la nueva coyuntura, pero también viene a cuestionar esta modernidad liquida planteada por Bauman "la sociedad moderna líquida es aquella en que las condiciones de actuación de sus miembros cambian antes de que las formas de actuar se consoliden en unos hábitos y en unas rutinas determinadas" (2013a, p.9), el aislamiento social abre la pauta para repensar sobre el tipo de sociedad que se tiene.

En la cruel pedagogía del virus, Boaventura de Sousa (2020) lleva a cuestionar sobre la manera de vivir ante de la COVID-19 y abre la puerta para repensar otras formas, pone en la discusión varios elementos y posibilidades de imaginar soluciones ante una realidad tan compleja, es una invitación a repensar sobre los espacios en los que uno se encuentra inmerso dentro de la sociedad e imaginar soluciones para reorientar el actuar, desde las universidades en cada una de sus áreas ha implicado 
una serie de discusiones sobre cómo continuar y con las medidas necesarias de seguridad, la tarea no ha sido sencilla porque aún la incertidumbre continúa presente. A principios del siglo XXI, Bauman (2015) en libro Vidas desperdiciadas hace una invitación a dirigir otra mirada al mundo moderno, de la misma forma que Boaventura De Sousa la hace al inicio de la pandemia.

La pandemia ha durado más de lo previsto, "otorga una libertad caótica a la realidad y cualquier intento de aprisionarla analíticamente está condenado al fracaso, ya que la realidad siempre va por delante de lo que pensamos o sentimos sobre ella" (De Sousa, 2020, p. 8), es por ello importante compartir lo aprendido y conocer otras experiencias que permitan construir un diálogo e intercambio de saberes sobre lo que se hace en diferentes espacios de las universidades. En este sentido, se comparte la experiencia de lo que ha implicado continuar con el proceso de intervención comunitaria en San Juan de Abajo desde el PIC en una coyuntura tan compleja como ha sido el confinamiento por la pandemia.

\section{Durante la pandemia}

La pandemia trastoca la dinámica de cada uno de los hogares y el entorno en el que se desenvuelven las personas, dentro del taller de intervención comunitaria el proceso se transfiguró y al mismo tiempo permitió imaginar otras posibilidades para intervenir en la comunidad, al inicio de la pandemia los primeros retos a enfrentar fueron 1) la adaptación de las clases al formato virtual, 2) la suspensión de visitas a la comunidad y 3) los limitados recursos económicos del taller. Las etapas de la 4-6 del programa se trataron de llevar en lo posible y haciendo compatible con los retos.

El primer reto implicó el cambio de la modalidad presencial a la virtual, una forma de tomar clase que era ajena a la totalidad del estudiantado y las profesoras. Nunca se habían usado aulas virtuales para el taller de intervención, en equipos se trabajaba la distribución tareas asignadas y en plenaria se compartían los resultados, se hacían los ajustes necesarios para las actividades a realizar en la comunidad, los contenidos y formas de trabajo se tuvieron que modificar para formato virtual, los alumnos tuvieron que adaptar su espacios privado para tomar clases y otros tantos tuvieron que incorporarse al mercado laboral para responder a las necesidades familiares que implicaba el aislamiento. Se utilizaron diversas plataformas o redes sociales, como el zoom, grupos de WhatsApp, videollamadas, entre otras. En este lapso, egresan e ingresan dos generaciones, se dio el cambio generacional dentro del taller, hubo quienes estuvieron trabajando con la comunidad, otros que sólo la conocían por comentarios de sus compañeros. En la discusión de los grupos focales, los alumnos que no lograron ir a la comunidad sintieron frustración, les faltó ese contacto con las personas, pero también implicó retos, sobre cómo dar la continuidad.

La suspensión de visitas a la comunidad fue otro de los retos, se plantean las preguntas ¿cómo hacer intervención comunitaria sin ir a San Juan de Abajo?, ¿cómo continuar con el proceso con la escasa conectividad de la comunidad? En un principio fue a través de llamadas telefónicas, después se hizo a través de la elaboración de fanzines y mensajes, imágenes o audios por WhatsApp, "Bertha la huácala viajera" dejo de visitar los hogares por la COVID-19. Una de las actividades sobresalientes durante el confinamiento fue la colecta de cobijas para la temporada invernal, se hizo una campaña con flyers que se difundieron en páginas de Facebook y a través de WhatsApp, mismas que se entregaron en diciembre de 2020 en la comunidad (Autora 2 y Autora 1, 2020).

El tercer reto sobre los limitados recursos económicos del taller resalta el esfuerzo de los alumnos para conformarse como CEIS y concursar por el Premio Municipal Juventudes 2019 por parte del Instituto Municipal de la Juventud (IMJ), como una 
apuesta para obtener recursos para el programa, lamentablemente, no lograron clasificar; en 2021 vuelven a participar, siendo finalistas. Si bien, no lograron el premio, su proceso es interesante, se constituyeron como grupo, se organizaron y en este último concurso, lo hicieron a pesar de las limitaciones de la pandemia, llegaron a ser finalistas y con ello, conocer otros colectivos. Esta experiencia de organización estudiantil persiste hasta hoy y les ha permitido aprender a hacer difusión de su trabajo, elegir representantes, el reto ahora es pasar la estafeta a las nuevas generaciones de DGI que no han estado involucradas en el proceso.

Desde la licenciatura de DGI a finales de 2020 se elaboró el proyecto "Pensar, crear y compartir. Nuevas formas de trabajo en contextos de aislamiento para la continuidad en procesos de intervención social" para participar en la convocatoria 2021 del Programa de Apoyo a Proyectos para Innovar y Mejorar la Educación (PAPIME), mismo que fue aprobado y ha permitido realizar las actividades durante el 2021, se continúa con la elaboración de fanzines, se retoma la presencia en la comunidad, la elaboración de macetas, cultivo de semillas, entrega de plantas, intercambio de saberes sobre plantas medicinales, realización de videos pequeños, prueba piloto de un podcast, encuentro entre egresados y alumnos, sistematización y evaluación del programa, entre otros. Los retos implican aprendizajes, imaginar y construir alternativas ante los obstáculos, surgen nuevas miradas y se visibilizan las ausencias o el reconocimiento de aspectos que son fundamentales para continuar avanzando, como el tema de cuidado.

La primera visita a la comunidad durante la pandemia se hizo en mayo de 2021, se realizó una propuesta de protocolo de seguridad para implementar medidas de cuidado entre la comunidad universitaria para evitar contagios, este protocolo fue revisado y comentado por las autoridades correspondiente, se solicitaron algunas modificaciones. A partir de ahí se comienza a visibilizar la importancia del cuidado y el trabajo que requiere, lo que conlleva a pensar en la ética de cuidado que conlleva asumir la responsabilidad que tienen todos en el cuidado y que no depende de unos cuantos.

La visita se redujo a sólo diez personas, ocho alumnas y dos profesoras, sirvió para retomar el contacto con la comunidad y señalar las actividades a realizar durante el siguiente semestre agosto-diciembre 2021, que coincide con el regreso paulatino de actividades semi-presenciales, este semestre se inicia con una serie de protocolos de bioseguridad. Desde el taller se incluye el tema de ética de cuidado como estrategia para fortalecer los protocolos a seguir, por ser el cuidado una de las formas para controlar la pandemia. Sin embargo, al incursionar en el tema se percibe su complejidad, el cuidado ha sido invisibilizado, relegado a la esfera privada y a cargo, en su mayoría, de las mujeres. La ética del cuidado permite reconocer que es una tarea de todos e intergeneracional, así como parte de la agenda pública, incluir dentro del taller implicó incursionar en un tema que no había sido considerado.

\section{Ética del cuidado ante el regreso a actividades presenciales}

El trabajo de cuidados se ha visibilizado con la pandemia, a pesar de estar siempre presente en la vida de cada persona, en la mayoría de las ocasiones es desapercibido, sin él no es posible sobrevivir, "el vínculo del cuidado es el que nos permite sobrevivir, crecer y desarrollarnos biológica y culturalmente. Pero el reconocimiento mutuo de la dignidad, de la necesidad de amor y estima es indispensable para llevar adelante una vida buena, una vida feliz" (Cortina, 2013, p.98). El cuidado es imprescindible para sobrevivir, la calidad con que se ofrece proporciona los elementos necesarios para tener una vida feliz. Sin embargo, la tarea no es fácil, el trabajo de cuidado es necesario en las diferentes etapas de la vida, 
lamentablemente, la responsabilidad queda en manos de algunas personas, porque existe una distribución desigual, si bien, todas las personas en algún momento de su vida requieren de trabajo de cuidados, no todas las personas lo hacen.

El trabajo de cuidados son todas aquellas actividades que permiten satisfacer la necesidades básicas y cotidianas de aquellas personas que no pueden valerse por sí mismas, como los niños, los enfermos, los adultos mayores, etc., "el trabajo de cuidados remite a todas aquellas actividades que tienen por objetivo la satisfacción de las necesidades básicas y cotidianas de otras personas" (Carrasquer, Torns y Grau, 2015, p.113), esta gran responsabilidad recae en gran medida en las mujeres ocasionando "repercusiones negativas en las trayectorias laborales y sociales a lo largo de sus vidas" (D'Argemir Cendra, 2016, p.11). porque reducen las actividades vinculadas al ocio que son una la ventana que dan sentido a la vida, en la medida que abren otras posibilidades de vida (Callejo, 2015, p.171), ante la carga del trabajo de cuidado no es posible desenvolverse en otros espacios.

Esta situación se complejiza con la pandemia, "la cuarentena será particularmente difícil para las mujeres y, en algunos casos, puede ser peligrosa. Las mujeres son consideradas «las cuidadoras del mundo», prevalecen en la prestación de cuidados dentro y fuera de las familias" (De Sousa, 2020, p.46). En el caso de la comunidad de San Juan de Abajo, el trabajo de cuidado se ha incrementado para las mujeres, tienen la responsabilidad de asistir a sus hijos en educación básica en sus clases en línea, otras tienen que buscar en la comunidad quién pueda compartir la señal de internet para que sus hijos puedan tomar sus clases, otras más se han incorporado al empleo temporal, sin dejar el trabajo de cuidado y en algunos casos son apoyadas por otras mujeres.

Entre una de las lecciones que deja el virus, es que el colonialismo y el patriarcado están vivos y se fortalecen en tiempos de crisis aguda (De Sousa, 2020, p.72), pero al mismo tiempo, abre la posibilidad de repensar y actuar hacia otras posibilidades, como el cuidado, "si la actitud cuidadora pertenece al ser más profundo de los seres humanos y hunde sus raíces en su ser animales, es evidente que debe ser propia tanto de mujeres como de varones" (Cortina, 2013, p. 45), el cuidado como una tarea de todos.

Pensar el trabajo de cuidados no sólo en la familia, sino en la esfera pública y privada implica una nueva forma organización social de los cuidados, "supone una ruptura epistemológica respecto a los usos anteriores del concepto de cuidado, que se limitaba a la esfera familiar, a las emociones y a la identidad de género" (D’Argemir Cendra, 2016, p.12) y el cuidado de sí mismo. La pandemia también muestra la ausencia del cuidado de sí mismo de algunas personas con enfermedades comórbidas y que generan una carga familiar, solo por el hecho de no cuidarse a sí mismas o no tomar las medidas de prevención o control. El cuidado de sí mismo es una práctica de autoformación del sujeto, es el ejercicio de uno sobre sí mismo mediante el cual se intenta elaborar, transformar, y acceder, a un cierto modo de ser, ocuparse de sí, cuidar de sí, permite conocerse, el cuidado es una práctica de libertad (Foucault, 1984). El cuidado como práctica de libertad en la pandemia, es cuidar de sí mismo y al mismo tiempo conlleva al cuidado de los otros, reduciendo el número de contagios y muertes, las medidas sanitarias más que una condición de control es la forma de retomar las actividades suspendidas y volver a retomar los espacios que permiten ejercer la libertad.

De acuerdo a Foucault (1984), la libertad es la condición ontológica de la ética; pero la ética es la forma reflexiva que adopta la libertad, el cuidado como práctica de libertad. Cortina señala que la ética también sirve "para recordar que los seres 
humanos necesitamos ser cuidados para sobrevivir y que estamos hechos para cuidar de los cercanos, pero también para recordar que tenemos la capacidad de llegar hasta los lejanos, creando vecindarios nuevos" (2013, p.54), la ética del cuidado sirve para sobrevivir, permite la reproducción de la vida, sin los cuidados no es posible. La pandemia en México ha dejado 284,381 muertes confirmadas por COVID-19 (Secretaría de Salud, 2020), aunque pueden ser más. Lamentablemente no sólo es un número, es una historia de vida que termina, para Bauman (2013 b) toda muerte supone la pérdida de un mundo, una pérdida para siempre, irreparable, pero corresponde a los vivos mantener viva la esperanza.

En este sentido, la ética del cuidado puede ayudar a mantener viva la esperanza, reconocer que involucra a todos, porque el cuidado no sólo es una tarea de las mujeres, Gilligan lo plantea de manera acertada e incorpora la voz de las mujeres con gran astucia, "la ética del cuidado y su interés en la voz y las relaciones es la ética del amor y de la ciudadanía democrática. También es la ética de la resistencia al daño moral" (2013, p.14), hacia aquellas personas a quienes se les asigna esta gran labor. La ética de cuidado cuestiona la imposición moral construida desde el patriarcado, "la implicación de los hombres en los trabajos de cuidados es un tema que hay que abordar, porque no es solo una cuestión de justicia vinculada a la equidad de género, sino también un imperativo social debido a las crecientes necesidades de cuidados" (D’Argemir Cendra, 2016, p.11) que requiere el trabajo conjunto de hombre y mujeres, así como el trabajo intergeneracional.

La ética del cuidado tiene que ir de la mano con una pedagogía del cuidado de las personas, donde todos sean partícipes en tarea de la reproducción de la vida, porque "no hay formas universales del cuidado, sino formas concretas, específicas, en las que se determinan los quiénes, los qué, los cómo y los para qué del cuidado de la vida" (Inclán, 2016, p. 29). Aquí la importancia de la ética del cuidado, porque la pedagogía del cuidado "recuerda que comer bien, vivir dignamente, que soñar, que desear, no es privilegio de unos pocos, sino responsabilidad de todos los que apuesten por la reproducción de la vida y por el cultivo de identidades sociales" (Inclán, 2016, p. 29) y la ética del cuidado permite orientar la acción de las personas en un marco de libertad a favor de la humanidad sin cargar la tarea a un solo género y dentro de las universidades no sólo a unas personas.

Promover la ética del cuidado entre alumnos universitarios se convierte un referente tanto en su vida personal como profesional sobre la importancia del cuidado en la reproducción de la vida en un contexto de libertad, donde la humanidad es el fin no un medio, aquí el llamado de Boaventura De Sousa (2020), cuestionar la forma en que se ha vivido para construir otras posibilidades. La ética de cuidado deberá tener un papel más relevante en la sociedad e ir de la mano con una pedagogía del cuidado, Bauman acertadamente señala que el estado del mundo puede ser diferente y depende en la medida de lo que uno haga, más que la influencia que el estado del mundo puede ejercer en lo que hacemos o dejamos de hacer: pasado, presente y futuro (2017, p.68), es necesario incluir la ética del cuidado en los espacios de educación superior más allá de la COVID-19.

Los protocolos de bioseguridad desde el taller de intervención comunitaria promueven una pedagogía del cuidado, se aborda el tema de la ética de cuidado, se conformaron equipos de cuidado y comisiones para dar cumplimiento a los protocolos, porque la ética de cuidado se basa la acción de las personas, se reconoce que no todos los alumnos universitarios comparten los mismos códigos de cuidados, se puede partir de los valores indispensables para alcanzar la madurez moral que señala 
Cortina: "justicia, autonomía, responsabilidad y compasión" (2013, p.46), como una práctica de libertad.

Incluir la ética de cuidado permite promover una pedagogía del cuidado en el cumplimiento de los protocolos de bioseguridad, a través de la conformación de equipos y comisiones los alumnos y profesores son responsables del cuidado de sí y de los demás. Los protocolos se cumplen de mejor manera porque establecen los códigos de cuidado que conllevan a una práctica de libertad dentro de la vida académica. Los alumnos son capaces de identificar y corregir acciones que pueden poner en riesgo la seguridad, por ejemplo, antes de la práctica un estudiante presentó síntomas, a pesar de no tener temperatura optó por seguir el protocolo de bioseguridad que señala que no se puede asistir, fue consciente que podía poner en riesgo al grupo y la comunidad, lamentablemente sus síntomas dieron positivo, desde la ENES se les da seguimiento a los casos, la recuperación del estudiante ha sido favorable. Por su parte, los equipos de cuidado no reportaron ningún síntoma o caso de COVID entre los asistentes durante los quince días posteriores. Los alumnos reconocen la importancia de seguir los protocolos de bioseguridad y que sus acciones individuales repercuten o favorecen en el cuidado, los equipos de cuidado y comisiones agilizaron y facilitaron el cumplimiento de los protocolos.

\section{CONCLUSIONES}

La pandemia por COVID-19 en México ha cobrado la vida de miles de personas, dejando vacíos en las familias y visibilizando el cuidado más allá de la esfera familiar, colocando en el ámbito público como una responsabilidad de todos. Aunque aún se puede observar a personas que no cumplen con las medidas básicas de cuidado, es necesario fortalecer los protocolos de seguridad a través de la ética de cuidado, respondiendo al llamado que no sólo es tarea de unos cuantos, sino de todos.

La apuesta es reducir el número las pérdidas por COVID-19, si bien el proceso de vacunación sigue avanzando, el virus continúa y no desaparecerá, se tendrá que aprender a vivir con él, mientras el cuerpo humano se hace resistente en su totalidad, el cuidado sigue siendo el mejor antídoto, implica el cuidado de uno mismo y de los otros, se requiere de una pedagogía del cuidado y aquí las universidades son bastión para lograrlo, a través de la diversidad de actividades que realizan, cada espacio se visualiza como una oportunidad para llevarla a cabo, se trata de una educación cívica orientada a la solidaridad y cooperación para el cuidado de todos.

Durante la pandemia se han generado varias alternativas posibles para continuar funcionando como sociedad, por ejemplo, la virtualidad se hizo parte de la vida de las personas, la solidaridad de los vecinos ante las familias que resultaron contagiadas, las estrategias de cuidado tanto en la esfera privada como la pública, entre otras, muestran la resiliencia que también se genera y se fortalece para enfrentar la pandemia, existe un código ético que permite enfrentar de mejor manera las dificultades que se presentan.

El compartir y conocer la diversidad de alternativas que han surgido durante la pandemia, conlleva a reflexionar y actuar de una mejor manera, pensando en el bien común y no solo de unos cuantos, es una práctica de libertad en la que todos pueden ser partícipes. Se presentó una experiencia de tantas que se desarrollan dentro de las universidades, sobre las implicaciones que tiene la pandemia en la vida universitarias y las estrategias que se han implementado para continuar con su labor, la tarea no ha sido sencilla, se apuesta a fortalecer las estrategias de enseñanza y aprendizaje ante contextos de aislamiento social. 


\section{REFERENCIAS BIBLIOGRÁFICAS}

Barbero, J. y Cortès F. (2005). Trabajo comunitario, organización y desarrollo social. Madrid: Alianza Editorial.

Bauman, Z. (2013a). Miedo Líquido. La sociedad contemporánea y sus temores. México: Paidós.

. (2013b). Vida Líquida. México: Paidós.

(2015). Vidas desperdiciadas: La modernidad y sus parias. México: Paidós.

. (2017). El arte de la vida. De la vida como obra de arte. México: Paidós.

Callejo, J. (2015). "El tiempo libre entre el trabajo y los cuidados." En Prieto, C. (Coord.), Trabajo, cuidados, tiempo libre y relaciones de género en la sociedad española (pp. 169-190). España: Grupo Editorial Cinca.

Carrasquer, P., Torns, T. y Grau, A. (2015). "El trabajo de cuidados entre el trabajo profesional y el tiempo de libre disposición personal. Perspectiva de género."

En Prieto, C. (Coord.), Trabajo, cuidados, tiempo libre y relaciones de género en la sociedad española (pp. 109-136). España: Grupo Editorial Cinca.

Carrillo, E. (12 de octubre 2021). AMLO llama a vacunarse y a regresar a clases presenciales en universidades Forbes. Consultado el 15 de octubre 2021. https://www.forbes.com.mx/politica-amlo-llama-a-vacunarse-y-regresar-aclases-presenciales-en-universidades/

Cortina, A. (2013). ¿Para qué sirve realmente la ética? México: Paidós.

D’Argemir Cendra, D. (2016). Hombres cuidadores: Barreras de género y modelos emergentes. Psicoperspectivas, 10 10-22. https://dx.doi.org/10.5027/psicoperspectivas-Vol15-Issue3-fulltext-750

De Sousa, B. (2020). La cruel pedagogía del virus. Buenos Aires: CLACSO. http://209.177.156.169/libreria_cm/archivos/La-cruel-pedagogia-del-virus.pdf

Diario Oficial de la Federación (DOF). (16 de marzo 2020). ACUERDO número 02/03/20. Consultado el 18 de octubre 2021. https://www.dof.gob.mx/nota_detalle.php?codigo=5589479\&fecha=16/03/202 0

Dirección General de Comunicación Social. (26 de agosto 2021). Regreso a la escuela, ¿híbrido o presencial? Consultado el 2 de septiembre 2021. https://www.dgcs.unam.mx/boletin/bdboletin/2021_696.html

El Financiero. (7 de agosto 2021). UNAM iniciará ciclo escolar 2021-2022 el 9 de agosto con clases a distancia. Consultado el 2 de septiembre 2021. https://www.elfinanciero.com.mx/nacional/2021/08/07/unam-iniciara-cicloescolar-2021-2022-el-9-de-agosto-con-clases-a-distancia/

ENES, Unidad León. (2020). Manual de Procedimiento de Bioseguridad para la Escuela Nacional de Estudios Superiores Unidad Léon \& San Miguel de Allende. Consultado el 24 de septiembre 2021. https://drive.google.com/file/d/1exd5JmSNbmkF-yx42S6tnrMnDXrgZe6K/view

Fornet-Betancourt, R.; Becker, H. y Gómez-Muller, A. (1984). "Entrevista con Michel Foucault." Revista Concordia 6, 96-116. Consultada el 21 de septiembre 2021. https://laciudadrevista.com/entrevista-con-michel-foucault-la-etica-delcuidado-de-uno-mismo-como-practica-de-la-libertad/

Gaceta UNAM. (20 mayo 2021). Lanza la UNAM App contra el coronavirus. Consultado el 28 de septiembre 2021. https://www.gaceta.unam.mx/lanza-launam-app-contra-el-coronavirus/ 
García, A. I. y Autora 1. (2018). Programa de Intervención Comunitaria [Documento interno]. Licenciatura en Desarrollo y Gestión Interculrurales. Escuela Nacional de Estudios Superiores, Unidad León.

García, A. I. y Autora 1. (2018). Primer informe del Programa de Intervención Comunitaria [Documento interno presentado a dirección]. Licenciatura en Desarrollo y Gestión Interculrurales. Escuela Nacional de Estudios Superiores, Unidad León.

García, A. I., Autora 1 y Autora 2. (2019). Segundo informe del Programa de Intervención Comunitaria [Documento interno presentado a dirección]. Licenciatura en Desarrollo y Gestión Interculrurales. Escuela Nacional de Estudios Superiores, Unidad León.

Gilligan, C. (2013). La ética del cuidado. Barcelona: Cuadernos de la Fundació Víctor Grífols i Lucas.

Gobierno de México. (s/f). Exceso de mortalidad en México. Consultado el 7 de octubre 2021. https://coronavirus.gob.mx/exceso-de-mortalidad-en-mexico/.

IMPLAN. (2019). Diagnóstico Municipal de León 2019. Consultado el 9 de septiembre 2021.

https://www.implan.gob.mx/pdf/sistema/Diagnostico_Municipal_de_Leon_201 9.pdf

(2014). Plan Municipal de Desarrollo León hacia el futuro. Visión 2040. León: IMPLAN.

Inclán, D. (2016). "Contrapuntos: La crueldad contra el cuidado (o cómo la violencia se hace cotidiana)." Bajo el Volcán, 16 (24), 13-31. https://www.redalyc.org/pdf/286/28647435002.pdf

INEGI (2021). Censo de Población y Vivienda 2020. Principales resultados por localidad (ITER). Consultado el 14 de septiembre 2021. https://www.inegi.org.mx/app/scitel/doc/descriptor/fd_iter_cpv2020.pdf

Autora 2 y Autora 1. (2019). Tercer informe del Programa dē Intervención Comunitaria [Documento interno presentado a dirección]. Licenciatura en Desarrollo y Gestión Interculrurales. Escuela Nacional de Estudios Superiores, Unidad León.

Autora 2 y Autora 1. (2020). Cuarto informe del Programa de Intervención Comunitaria [Documento interno presentado a dirección]. Licenciatura en Desarrollo y Gestión Interculrurales. Escuela Nacional de Estudios Superiores, Unidad León.

Secretaria de Desarrollo Social (s/f). Información de Localidad San Juan de Abajo. $\begin{array}{lllll}\text { Consultado el } & 7 & \text { de } & \end{array}$ http://www.microrregiones.gob.mx/catloc/contenido.aspx?refnac=110200451

Secretaría de Salud. (2020). Covid-19 México. Datos Abiertos Dirección General de Epidemiología. Consultado el 16 de octubre de 2021. https://datos.covid19.conacyt.mx/\#DOView

Secretaria de Salud. (s/f). Calendario de Vacunación. Consultado el 18 de octubre 2021. http://vacunacovid.gob.mx/wordpress/calendario-vacunacion/ 